Discussion Papers of the

Max Planck Institute for

Research on Collective Goods

2020/23

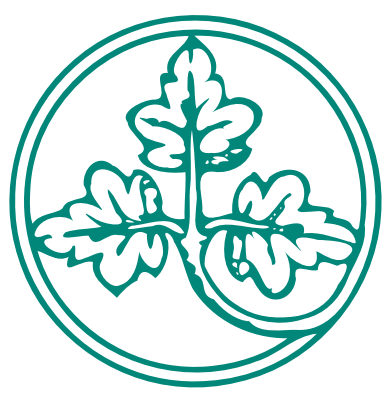

Does the Fundamental

Transformation Deter Trade?

An Experiment

Christoph Engel

Eric Helland 


\title{
Does the Fundamental Transformation Deter Trade? An Experiment
}

\author{
Christoph Engel / Eric Helland
}

September 2020 


\title{
Does the Fundamental Transformation Deter Trade? An Experiment
}

\begin{abstract}
Oliver Williamson has coined the term "fundamental transformation". It captures the following situation: before they strike a deal, buyer and seller are protected by competition. Yet thereafter they find themselves in a bilateral monopoly. With common knowledge of standard preferences, both sides conclude the contract regardless if its expected value exceeds their outside options. We run an experiment to test whether additional behavioral reasons deter mutually beneficial trade. If the risk materializes, another individual makes a windfall profit. She does so by intentionally exploiting the first individual. The first individual is let down, although she has knowingly exposed herself to this risk. Participants sell the opportunity to enter the contractual relationship at a price below its expected value. This effect is driven by risk aversion, and already present if the risk is stochastic. Behavioral effects are heterogeneous. About a quarter of participants exhibit the hypothesized additional deterrent effect.
\end{abstract}

Keywords: fundamental transformation, bilateral monopoly, sunk cost, Oliver Williamson, windfall profit, exploitation, let down aversion

JEL: B21, C91, D22, D43, K12, L12, L14

* Helpful comments by Sebastian Kube and Pascal Langenbach on an earlier version are gratefully acknowledged. 


\section{Does the Fundamental Transformation Deter Trade? An Experiment}

\section{Introduction}

Most deep insights are simple - in retrospect. But gaining the insight takes ingenuity. And alerting others to the insight requires the sovereign command of language. All of these hold for one of the terms coined by Nobel Prize winner Oliver Williamson. Entering a contractual relationship can have the effect of a "fundamental transformation" (Williamson 1985). While ex ante multiple buyers can choose with whom of multiple sellers to trade, once the deal has been struck it transforms into bilateral monopoly. The buyer must live with this one seller, and the seller must live with this one buyer. The effect obtains if, once the contract has been concluded, it would be technically impossible, prohibitively costly, or illegal to turn to a different interaction partner.

One cause of this fundamental transformation, that Oliver Williamson has been particularly interested in, is transaction specific investment (Williamson 1985). Such investment is defined by being worthless, or at least much less valuable, if not used for fulfilling the contract in question, or further developing this business relationship. Yet this is only one potential cause of the transformation. It can also become impossible to turn away from a contracting partner if the first interaction required sharing sensitive information. A legal application stems from the prohibition, for a law firm, to represent the opponent of one of its clients. This legal rule effectively forces law firms and clients into stable relationships. The fundamental transformation can also be brought about strategically. A classic illustration is bundling, for instance of cheap copying machines with costly, proprietary toner cartridges (Adams and Yellen 1976, McAfee, McMillan et al. 1989, Nalebuff 2004).

Once the fundamental transformation has taken place, both sides to the deal are "locked in" (Farrell and Shapiro 1989, Liebowitz and Margolis 1995, Farrell and Klemperer 2007). They have made themselves vulnerable to the fate and to the goodwill of their contracting partner. If their partner goes bankrupt, or closes this line of business, they are in trouble. Trouble also looms large if a change in circumstances gives the contracting partner power to exploit the dependence. In the literature, this is called a hold-up situation (Ellingsen and Johannesson 2004, Hoppe and Schmitz 2011, Dufwenberg, Smith et al. 2013). A graphic illustration is the debate between Coase (2000) and a team most frequently represented by Benjamin Klein over the reason for General Motors to acquire Fisher Body in 1926 (Alchian and Demsetz 1972, Klein, Crawford et al. 1978, Klein 1988, Klein 2000); Klein and his co-authors argue that Fisher Body was taking advantage of GM's dependence on their bodies, which GM ended by vertical integration.

For a person intended to maximize profit, lock-in is just a contingency. Such a person compares the profit from staying alone with the expected benefit from entering the relationship. If the event space and probabilities are well defined, this is a simple exercise in calculation. If not, she replaces objective with subjective probabilities, and an objective with a subjective event space (Savage 1954). 
Yet from a behavioral perspective, the decision to enter the relationship may look far more fraught. Understanding to which degree this is the case, and under which circumstances, is the topic of this paper. Does lock-in aversion deter efficient trade? There is quite a list of behavioral regularities that might have this effect.

When deciding between a safe, but potentially less profitable, option and letting the fundamental transformation take place, the decision-maker incurs a risk. In the simple most situation, this risk is stochastic. No contractual partner is afraid of being taken advantage of. But they foresee that, in retrospect, entering the relationship may have been a bad idea. They could refrain from doing so because they are too strongly averse to risk. They might also construct the expected gains from trade as a reference point (Kahneman 1992, Köszegi and Rabin 2006, Hart and Moore 2008), and might anticipate loss aversion should the risk materialize (Kahneman, Knetsch et al. 1991, Tversky and Kahneman 1991). Or they might be concerned that, should the risk materialize, they will regret having entered the relationship. Regret might reduce their self-esteem, which they anticipate (Zeelenberg, Beattie et al. 1996, Zeelenberg and Beattie 1997, Van de Ven and Zeelenberg 2011).

In a contractual relationship, one partner's loss can be another partner's gain. Even if this gain is not resulting from one partner strategically exploiting the other, they might still dislike that an exogenous event changes the intended balance of outcomes. Specifically they might see this as an instance of disadvantageous inequity, in the sense of Fehr and Schmidt (1999), which they anticipate to dislike.

If the risk consists, at least partly, of becoming vulnerable to exploitation by the contracting partner, intentions come into play. It is possible that one side anticipates the eventuality, but is not concerned as she trusts the good-naturedness of her partner. If she does not deem the contracting partner sufficiently trustworthy though, she may loathe being let down, and rather shy away from the relationship (Dufwenberg and Gneezy 2000).

In this project, we use experimental methods to gauge the degree by which these behavioral effects stand in the way of mutually beneficial, and hence efficient, trade. Our measure for deterrence is the price at which participants are willing to sell the opportunity to be in the contractual relationship. The further this price is below the expected value, the more participants shy away from mutually beneficial trade, for one of the behavioral reasons that we test. Each participant first decides in a Baseline in which she interacts with Nature. The only risk is stochastic. This gives us the possibility to take the participant's degree of aversion to this type of risk out of the equation.

Thereafter within subjects each participant is exposed to one of four treatments. These treatments are randomly assigned between subjects. Choices in the first part have no material consequences in this second part. The experiment is designed to isolate the following four channels: (a) another participant may gain a windfall profit if the risk materializes; (b) whether she does, depends on a choice she makes; she must thus decide to exploit the opportunity to her advantage; (c) the risk is reciprocal: the second participant who may potentially exploit the first is, by an independent draw of Nature, herself vulnerable to being exploited by the first participant; (d) both participants must have voluntarily entered the relationship, knowing that it comes with the opportunity to exploit the partner, and the risk of being exploited by 
her. Arguably Oliver Williamson's fundamental transformation is simultaneously characterized by all four effects, and by the behavioral effects they might trigger. In the Windfall treatment, there is only (a). In the Exploitation treatment, there are (a) and (b). In the Bilateral treatment, there are (a), (b) and (c). In the Exchange treatment, all four effects are present.

On average, irrespective of the within and the between participants manipulation, prices are slightly, but significantly below the expected value of the contract. For the Baseline and all treatments except Windfall, this is explained by risk aversion. In the Windfall condition, participants ask for a significantly higher price than in Baseline in exchange for not being in the contractual relationship. This is the opposite of deterrence. It suggests that participants find it appealing that, if the risk materializes, money is not destroyed, but redistributed. In the Exploitation and Bilateral conditions, they ask for a significantly lower price than in the Baseline. In these treatments we thus find deterrence. Note that this result can only be explained by behavioral effects. Unless participants expect each and every other participant to harm them when given the opportunity, the expected value of the contract is higher than in the Baseline (where harm is mechanical if the risk materializes). The comparison with the Baseline and the Windfall treatment suggests that participants dislike being the victim of intentional harm. Average prices in the Exchange condition are not significantly different from those in the Baseline.

Average effects do, however, mask pronounced heterogeneity. In all treatments, we find participants who ask for a lower price in the treatment than in the Baseline, and others who ask for a higher price. Yet distributions differ. In Windfall, participants predominantly ask for more money. This fits the efficiency motive. The opposite effect dominates in the Exploitation and Bilateral treatments. In these treatments, intentions matter. Participants dislike exposing themselves to willful harm inflicted by another participant. Finally in the Exchange treatment, the dominant reaction to treatment is the same as in the Baseline. In this treatment, apparently behavioral effects pointing into opposing directions compete with each other: a participant risks being let down by a contractual partner; but she has voluntarily exposed herself to this risk. The result suggests that these effects cancel out.

Our evidence thus adds behavioral detail to Oliver Williamson's picture. The fundamental transformation is an obstacle to efficient trade even if, in expectation, the ensuing risk of exploitation is worth taking. The deterrent effect does not only result from risk aversion. It is compounded by aversion against being the victim of intentionally inflicted harm. Yet the additional, behavioral, deterrence is not universal. It only affects a fraction of the population. Yet in the lab, this fraction is sizeable.

The remainder of the paper is organized as follows: in section 2 we relate our experiment to the literature, and define our contribution. In section 3 we develop hypotheses. In section 4 we report the details of the design. Section 5 is devoted to results. Section 6 concludes with discussion. 


\section{Contribution}

There is a series of three related experimental papers that also investigate Williamson's fundamental transformation. These papers start from the theoretical contribution by Hart and Moore (2008). The critical element of their model is mutual incompleteness of the contract. The buyer is free to choose a minimum price or to pay more. She can, however, exclude price adjustments by choosing a "rigid" contract. The seller either faces low or high production cost. She determines the buyer's profit by choosing quality. The model is interested in "shading". At a small cost for herself, the seller can strongly reduce the buyer's profit. In behavioral terms, this is an instance of costly punishment (Güth, Schmittberger et al. 1982, Andreoni, Harbaugh et al. 2003, Casari and Luini 2009, Almenberg, Dreber et al. 2011, Balliet, Mulder et al. 2011). The model expects the propensity to shade to depend on the seller's reference point, which, in turn, is determined by the choice of contract. The model assumes that the seller evaluates the price chosen by the buyer once the uncertainty about the state of nature has been resolved in the light of this reference point.

In the lab, the main prediction of the model is supported. There is little shading if the buyer chooses a "rigid contract". With this contract, there is no trade at all if the seller faces high production cost. If the buyer chooses a "flexible contract", in the bad state of nature the buyer may adjust the price upwards. The less she does, the more the seller is inclined to produce low quality (Fehr, Hart et al. 2011). Yet the difference in shading between contracts disappears if buyers and sellers are randomly matched, rather than determined by competition (Fehr, Zehnder et al. 2009, Fehr, Hart et al. 2011: 516f.). By contrast the predicted effects still go through if there is the additional possibility to conclude informal agreements, or to renegotiate the contract after the state of nature is revealed (Fehr, Hart et al. 2015).

These are important findings. But in a way these experiments address the second question before the first. They investigate how contractual partners react once they find themselves in a bilateral monopoly. These papers only report in passing how the prospect of bilateral monopoly affects the choice of contract. If there is competition between buyers and sellers, about half of them choose the rigid contract, with $38 \%$ in the beginning, and $56 \%$ in the final period (Fehr, Hart et al. 2011: 509). If there is no competition, only $28 \%$ choose the rigid contract in the first experiment (Fehr, Hart et al. 2011: 517), and initially $21 \%$ in the second experiment. By the end of that experiment, this fraction goes down to $9 \%$ (Fehr, Zehnder et al. 2009: 571). ${ }^{1}$ By contrast we are chiefly interested in the choice of initial contract, and isolating its behavioral determinants. Using a multiple price list, we elicit participants' willingness to accept the risk of exploitation that is inherent in the fundamental transformation.

Further experimental papers are more remote. Blankenborg, Kaplan et al. (2012) find that the risk of a hold-up situation only deters trade if the second mover has considerable bargaining power. Dufwenberg, Smith et al. (2013) implement a sequential game with three stages. At the first stage the first mover can terminate the game, at the second the second mover can. If the second mover does, the outcome is efficient and both gain the same amount. The treatment difference is in the third stage. If the first mover has the option to punish the second mover, at a small cost to herself, she is considerably more likely not to terminate the game at

\footnotetext{
${ }^{1}$ In Fehr, Hart et al. (2015) the fraction of rigid contracts is not reported.
} 
the origin. Hoppe and Schmitz (2011) show that, against predictions from standard theory, option contracts can mitigate the hold-up problem. Sloof, Sonnemans et al. (2004), Ellingsen and Johannesson (2004) and Erlei and Siemer (2014) are not interested in the formation of the bilateral relationship, but in investment choices in anticipation of later bargaining over the surplus.

\section{Design}

The main experiment combines a within subjects with a between subjects design. Treatments are summarized in Table 1. All participants are first assigned to the Baseline treatment. When initially assigned subjects know only that the experiment has multiple parts, but not what these parts are about. In the Baseline, participants decide at the first stage which amount they request for giving up the opportunity to participate in the second stage. Using the strategy method (Selten 1967), we elicit their willingness to accept by way of a multiple price list in the spirit of Becker, DeGroot et al. (1964). They participate in the second part of the experiment provided the minimum price they have chosen is smaller than the random price that the computer selects from a uniform distribution in the range $[0,100]$. Provided they enter the second stage, they obtain 100 experimental currency units (ECU) with probability $80 \%$, and 10 ECU with probability $20 \%$. Hence the expected value of participating in this stage is $82 \mathrm{ECU}$.

\begin{tabular}{|l|c|c|l|l|}
\hline & $\begin{array}{l}\text { human } \\
\text { beneficiary }\end{array}$ & $\begin{array}{l}\text { room for } \\
\text { exploitation }\end{array}$ & $\begin{array}{l}\text { room for } \\
\text { reciprocal } \\
\text { exploitation }\end{array}$ & $\begin{array}{l}\text { voluntary } \\
\text { consent }\end{array}$ \\
\hline Baseline & & & & \\
\hline Windfall & $\mathrm{x}$ & & & \\
\hline Exploitation & $\mathrm{x}$ & $\mathrm{x}$ & & \\
\hline Bilateral & $\mathrm{x}$ & $\mathrm{x}$ & $\mathrm{x}$ & \\
\hline Exchange & $\mathrm{x}$ & $\mathrm{x}$ & $\mathrm{x}$ & $\mathrm{x}$ \\
\hline
\end{tabular}

Table 1

Treatments

In the second part of the experiment, participants are in one of four treatments. All treatments differ from the Baseline by the fact that, if the bad state of Nature obtains, another experimental participant gains a windfall. In the Windfall treatment, this effect is mechanical. By contrast, in the remaining treatments, in the bad state of Nature another participant has power to take $90 \mathrm{ECU}$. In the Exploitation treatment, the participant who has power to take differs from a second participant from whom the first participant can take $90 \mathrm{ECU}$ in case the bad state of Nature obtains (in this relationship). In the Bilateral and in the Exchange treatments, two experimental participants are matched. In the Bilateral treatment, matching is ex post. One other participant who has decided to accept the contract is randomly matched. By contrast in the Exchange treatment, matching is ex ante. ${ }^{2}$

\footnotetext{
${ }^{2}$ If the second part is payoff relevant, the second stage is only implemented if both participants in the ex ante match have decided to participate in this stage. Otherwise they receive the number that the computer has randomly chosen. This is also how we proceed if the number of participants in a session is odd, for the one unmatched participant.
} 
In the interest of obtaining full data, we use the strategy method a second time if the payoff relevance in the bad state of Nature depends on the decision of another participant. We elicit this choice conditional on the opportunity presenting itself.

To preempt hedging, and interference between choices in the first and the second part of the experiment, participants learn that either the first or the second part is paid out, with equal probability. All random draws are independent from each other. All are executed at the very end of the entire experiment. All feedback is withheld until the participants have made all choices, to preserve independence.

In the interest of having more scope for finding the behavioral effects that motivate our hypotheses, after the main experiment we run a series of standard tests: risk aversion, using the standard test by Holt and Laury (2002); loss aversion, using the test by Gächter, Johnson et al. (2007); regret aversion, using the test by Schwartz, Ward et al. (2002); social value orientation, using the standard test by Murphy and Ackermann (2014); and trust and trustworthiness, adapting the test by Berg, Dickhaut et al. (1995). We finally ask which minimum price this participant believes one other participant to have chosen in the second stage of the experiment. In the Exploitation, Bilateral and Exchange treatments, we also ask whether the participant believes that the other participant with whom they have been matched has decided to take 90 ECU from them, should the opportunity present itself. Beliefs are incentivized. For detail, we refer to the instructions in the appendix.

In a pilot, we had the impression that a substantial fraction of participants might not have understood the design. We have reacted with a series of safeguards: (1) in the instructions we extensively explain the mechanism used to elicit willingness to pay; (2) we have participants solve two control questions; (3) we explicitly inform participants about the expected value of concluding the contract, to avoid that results are influenced by calculation errors, or the inability or unwillingness to calculate the profit maximizing choice. We acknowledge that this number can work as an anchor. Yet if participants do the calculations, they have the same information. And most importantly, we are chiefly interested in the difference between choices in the Baseline and in the respective treatment. This dependent variable cannot be affected by a potential anchor, as the potential anchor is held constant in the first two parts of the experiment. For all details regarding the design of the experiment we refer to the instructions in the appendix.

The experiment has been run in the lab of the Max Planck Institute for Research on Collective Goods in Bonn. Participants have been invited with software hroot (Bock, Baetge et al. 2014). The experiment has been programmed with software zTree (Fischbacher 2007). 200 students of various majors participated who have been randomly selected from a pool of approximately 6000 participants. 112 (56\%) were female. Mean age was 25.01 years. Participants on average earned $19.40 €$ (equivalent to $21.38 \$$ on the first day of the experiment). As not all invited participants showed up, the number of participants varies per treatment. We have 47 participants in the Windfall treatment, 50 in Exploitation, 54 in Bilateral and 49 in the Exchange treatment. 


\section{Hypotheses}

Standard Preferences. If participants hold standard preferences themselves, and expect other participants to hold standard preferences as well, and to also expect that others expect them to hold such preferences, they expect that others will seize the opportunity to make a higher profit if it presents itself. Hence if they interact with another human participant and the random draw makes it possible for this participant to exploit them, they expect this to happen. In the experiment, the probability is known with which exploitation is possible. Therefore participants can calculate the expected value of the risky option. They are indifferent between this option and its certainty equivalent. This gives us

Hypothesis 1: a) Participants only prefer the safe outside option if its value exceeds the expected value of the risky option.

b) There are no treatment differences.

Risk aversion, loss aversion, and regret aversion. If participants are risk averse, their utility from a lottery is smaller than its certainty equivalent. On average, participants of experiments have been shown to be risk averse (Cartwright 1971, Holt and Laury 2002, Fullenkamp, Tenorio et al. 2003, Dohmen, Falk et al. 2011, Charness and Gneezy 2012). This should affect their willingness to accept the fundamental transformation. In this perspective, avoiding the fundamental transformation can be interpreted as insuring oneself against being locked in. The effect should even be more pronounced if participants are, additionally, averse to losses, and if they interpret the sure outcome in case they avoid the fundamental transformation as a reference point (Tversky and Kahneman 1991, Köszegi and Rabin 2006). Participants might also anticipate that, should the risk materialize, they will regret having entered the relationship. Regret might reduce their self-esteem, which they anticipate (Zeelenberg, Beattie et al. 1996, Zeelenberg and Beattie 1997, Van de Ven and Zeelenberg 2011).

These considerations yield

Hypothesis 2: a) The willingness to accept the fundamental transformation is below its expected value.

b) There are no treatment differences.

Inequity aversion. The Windfall treatment differs from the Baseline by the effect of the fundamental transformation. If the risk materializes, the participant who has been willing to lock herself in not only loses money herself. This money goes to another participant who, otherwise, would have had the same payoff as herself. It has been shown that many participants are averse to inequity, in particular if it is to their detriment (Fehr and Schmidt 1999, Blanco, Engelmann et al. 2011).

Now with respect to a third participant, the decision-maker is herself in the position of potentially making a windfall gain. Yet those two relations are unrelated and the design keeps the probability that the risk materializes small. More importantly, the active participant has no influence on receiving a windfall gain, while it is in her power to prevent another participant from gaining extra money. Finally, if windfalls occur in both dimensions, the active participants potentially experience disadvantageous inequity in one direction, and advantageous inequity 
in the other. Most participants are more sensitive to the former than to the latter. Hence even if both windfalls co-occur, the behavioral effects do not cancel out, but compound. ${ }^{3}$

Efficiency. The treatment effect could however also point in the opposite direction, as in Windfall the money goes to another participant, while in the Baseline it is lost. Participants might prefer that another participant makes a windfall gain over nobody benefitting. One could see this as an instance of a preference for efficiency (cf. Engelmann and Strobel 2004).

As we have competing hypotheses, we cautiously predict

Hypothesis 3: Willingness to accept the fundamental transformation differs between the Windfall treatment and the Baseline.

Let down aversion. In the Windfall treatment, if the risk materializes another participant gains extra money. Yet the resulting inequity is mechanical. This is different in the Exploitation treatment. In this treatment, whether the active participant loses money is a choice of another, randomly determined participant. The fundamental transformation thus puts the active participant at the mercy of another experimental participant. It has been shown that individuals are averse to being exploited (Dufwenberg and Gneezy 2000).

Generalized trust. On the other hand, participants might hold generalized trust in the population of experimental subjects, and deem it less than certain that they will be exploited.

As plausible behavioral effects point into opposite directions, we again cautiously posit:

Hypothesis 4: Willingness to accept the fundamental transformation differs between the Exploitation and the Windfall treatment.

Hold-up. In the Exploitation treatment, if the risk materializes, one participant is at the mercy of another. Yet the risk is unilateral. A may be exploited by $B$, but $B$ does not run the risk to be exploited by $A$. A may exploit $C$, and $D$ may exploit $B$, but these are unrelated contingencies. This is different in the Bilateral treatment. Nature matches two individuals who have (independently and with no information about the person with whom they will be matched) chosen to run the risk of the fundamental transformation. If the risk materializes for both of them, either of them may exploit the other. This design places participants in a hold-up situation. The existing experimental evidence is tentative: under some circumstances trade with the prospect of a hold-up becomes less likely (Ellingsen and Johannesson 2004, Dufwenberg, Smith et al. 2013). With our design, we have the possibility to discriminate between the risk of exploitation and the hold-up situation, and generate a cardinal measure for the difference between both.

\footnotetext{
${ }^{3}$ Note that, with $90 \%$ probability, this result also holds if the participant in question does not compare payoff per relationship, but total payoff. If $A$ takes from $B$, in this relation $B$ earns 10 . If she happens to have a chance to take from $C$, and does so, in that relationship, she earns 90 . Her total earnings (from this part of the experiment) are thus 100 . This is more than $C$, and less than $A$, unless $C$ also has the opportunity to take and acts upon it, and $A$ is the victim of taking from yet another participant. Either opportunity only presents itself with probability $10 \%$. Both of them only present themselves simultaneously with probability $1 \%$.
} 
Specific trust. In Exploitation, there is room for reciprocal respect for the earnings of one's counterpart. Participants might interpret the situation as one of coordination, and expect coordination on the outcome where neither participant exploits the other. There is, however, no institutional safeguard. But the participant need not rely on trust at the population level either. It suffices if she believes in the motivating effect of depending on each other. We once more have no directed hypothesis, and posit

Hypothesis 5: Willingness to accept the fundamental transformation differs between the Bilateral and the Exploitation treatment.

Voluntary trade. In Oliver Williamson's thinking, the fundamental transformation does not collapse with a hold-up situation. He is not exclusively considering the situation ex post, where one individual is at the mercy of the other. Rather he is interested in the decision to bring the transformation about when it could have been avoided. It is not a move of Nature that creates the hold-up situation; individuals bring it about by mutual consent. They decide to replace a situation where they remain independent with a bilateral monopoly. In the experiment we capture this difference by the matching protocol. In the Bilateral treatment, we only match participants who have decided to run the risk of exploitation. Yet they have made this decision independently, and matching is at random. By contrast in the Exchange treatment, participants are matched before they decide about the fundamental transformation. Behaviorally, the difference is one of trust. By accepting the fundamental transformation, the matched participants put trust into each other.

This may trigger two competing effects (Berg, Dickhaut et al. 1995, Johnson and Mislin 2011). Participants may be even more deterred from entering the fundamental transformation as the materialization of the risk is also a breach of trust: they may loathe being betrayed (Bohnet and Zeckhauser 2004, Bohnet, Greig et al. 2008). They may also be concerned that only participants planning to take self-select into the second stage of the experiment. Yet they may also be less deterred as they do trust their anonymous partner and expect that they will not be let down by someone to whom they have made themselves vulnerable voluntarily. We thus do not have a directed hypothesis either, but predict

Hypothesis 6: Willingness to accept differs between the Bilateral and the Exchange treatments.

\section{Results}

Treatment effects on means Figure 1 summarizes treatment effects. In the Baseline and in all treatments, the average price participants demand for not entering the second stage, i.e. the contract that is fraught with the risk of $90 \mathrm{ECU}$ going to another participant, is slightly below its expected value of 82 . The difference from the expected value is significant for the Baseline (t-test, $\mathrm{N}=200, \mathrm{p}<.001$ ) and for all treatments except Windfall (Exploitation $\mathrm{N}=50, \mathrm{p}=.0024$; Bilateral $\mathrm{N}=54, \mathrm{p}=.001$; Exchange $\mathrm{N}=49, \mathrm{p}=.0535$ ). This rejects $\mathrm{H}_{1}$ : on average, participants prefer to exchange the contractual relationship against a certain payment that is slightly below the expected value of entering the relationship. Recall that we explicitly told them the 
expected value, and explained what it meant. Hence in the Baseline and three of the treatments, participants knowingly accept a lower expected profit.

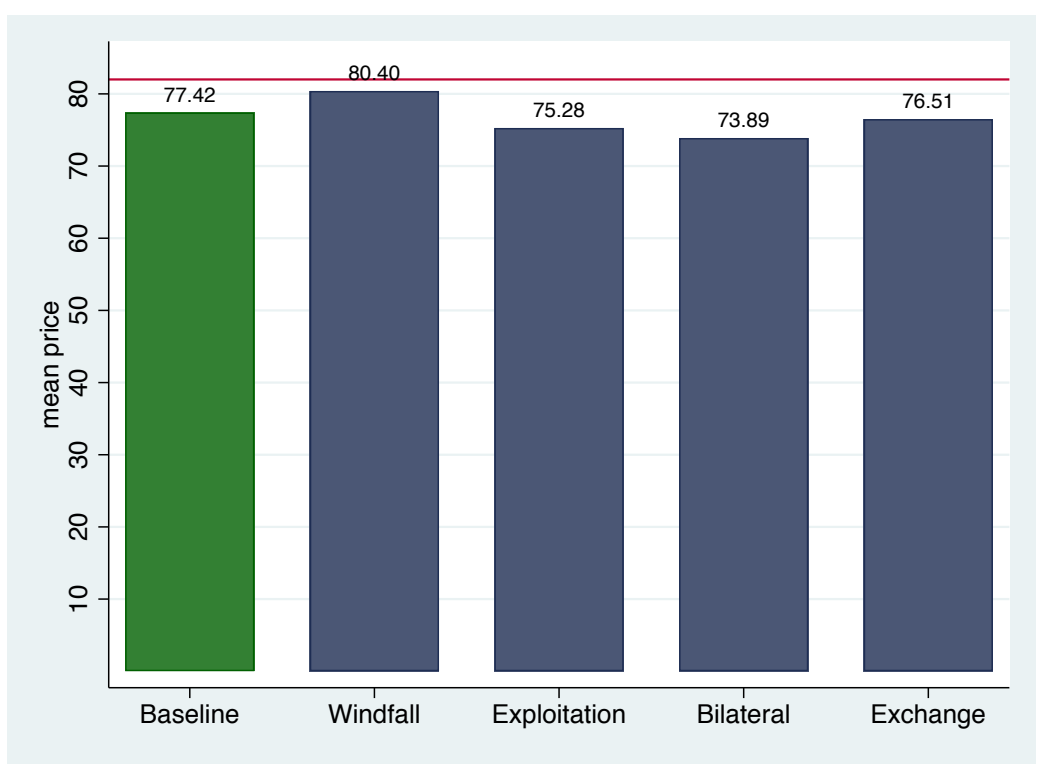

Figure 1

Treatment Effects on Prices Demanded for Not Entering the Contractual Relationship red line at 82: expected value of the contractual relationship

In $\mathbf{H}_{\mathbf{2}}$ we had expected that many participants would sell the opportunity to enter the contractual relationship below its expected value. The regressions in Table 2 show that the main reason is risk aversion. It explains choices both in the Baseline (models 1 and 3) and in those treatments in which choices are significantly below the expected value (models 7 and 9). From the fact that risk aversion also explains choices in the treatments we learn that individuals' risk attitude is not masked by additional motives that can only matter in the treatments. Except for model 5, loss aversion has at most a weakly significant effect (Baseline: models 2 and 3; all treatments: models 5 and 6). Regret aversion never explains choices, neither as the single explanatory variable, nor in conjunction with risk aversion and loss aversion. ${ }^{4}$

\begin{tabular}{|l|l|l|l|l|l|l|l|l|l|}
\hline & \multicolumn{3}{|c|}{ Baseline } & \multicolumn{3}{c|}{ All Treatments } & \multicolumn{3}{c|}{ Exploitation, Bilateral, Exchange } \\
\hline & model 1 & model 2 & model 3 & model 4 & model 5 & model 6 & model 7 & model 8 & model 9 \\
\hline $\begin{array}{l}\text { risk } \\
\text { aversion }\end{array}$ & $-5.394^{* *}$ & & $-4.761^{* *}$ & -4.545 & & -3.539 & $-7.153^{* *}$ & & $-5.953^{*}$ \\
\hline loss & $(2.258)$ & & $(2.316)$ & $(2.851)$ & & $(2.919)$ & $(3.475)$ & & $(3.556)$ \\
aversion & & $-1.131^{*}$ & $-1.012^{*}$ & & $-1.467^{* *}$ & $-1.465^{*}$ & & -1.397 & -1.323 \\
\hline cons & & $(.606)$ & $(.601)$ & & $(.723)$ & $(.758)$ & & $(.857)$ & $(.901)$ \\
& $80.045^{* * *}$ & $80.765^{* * *}$ & $82.791^{* * *}$ & $78.538^{* * *}$ & $80.764^{* * *}$ & $82.500^{* * *}$ & $77.857^{* * *}$ & $79.291^{* * *}$ & $81.379^{* * *}$ \\
& $(1.298)$ & $(2.051)$ & $(2.063)$ & $(1.628)$ & $(2.447)$ & $(2.600)$ & $(1.854)$ & $(2.859)$ & $(3.026)$ \\
\hline $\mathrm{N}$ & 189 & 199 & 188 & 189 & 199 & 188 & 146 & 153 & 146 \\
\hline
\end{tabular}

Table 2

Explaining Choices with Risk and Loss Aversion

OLS

dv: models 1 - 3: choice in Baseline; models 4-9: choice in treatments risk aversion: CRRA score, 0 is risk neutral, 11 participants inconsistent loss aversion: switching point: the higher the more averse to losses, 1 participant inconsistent standard errors in parenthesis $* * * p<.001, * * p<.05, * p<.1$

\footnotetext{
4 These additional regressions are available from the authors upon request.
} 
In $\mathbf{H}_{\mathbf{3}}$ we had expected that choices in the Windfall treatment significantly differ from choices in the Baseline. If the predominant motive were inequality aversion, participants should sell the opportunity to enter the contractual relationship at a lower price in the Windfall treatment. If, by contrast, participants are chiefly motivated by the fact that the money is not lost and another participant benefits, i.e. by an efficiency motive, participants should sell the opportunity at a higher price. We do find the latter. Participants on average ask for 3.830 more, which is a significant difference (t-test testing the null hypothesis that this difference is zero, $N=47, p=.0212$, two-sided). As already suggested by the differences between models $4-6$ on the one hand and models $7-9$ of Table 2 on the other, in the regressions of Table 3 we find that, in the Windfall treatment, differences between choices in the first and second part of the experiment are not explained by risk aversion. In model 2, we do find a weakly significant ( $p=.064$ ) effect of social value orientation. Interestingly, it is positive. The more a participant is socially minded, the more, not the less she is likely to ask for more money to sell the opportunity to enter the contractual relationship, compared with her own choice when the money in the bad state of Nature goes back to the experimenter. This fits the explanation that participants care about others having the opportunity to make some extra money.

\begin{tabular}{|l|l|l|}
\hline & model 1 & model 2 \\
\hline risk aversion & 3.480 & 3.577 \\
& $(4.293)$ & $(4.161)$ \\
\hline social value orientation & & $.240 *$ \\
& & $(.126)$ \\
\hline cons & 1.478 & -2.773 \\
& $(2.932)$ & $(3.610)$ \\
\hline $\mathrm{N}$ & 43 & 43 \\
\hline
\end{tabular}

Table 3

Explaining Difference between Baseline and Windfall Treatment OLS $\mathrm{dv}$ : choice in Windfall treatment - choice in Baseline risk aversion: CRRA score, 0 is risk neutral, 11 participants inconsistent social value orientation: 0 is selfish standard errors in parenthesis $* * * p<.001, * * p<.05, * p<.1$

In $\mathbf{H}_{4}$ we had predicted that participants in the Exploitation treatment want to sell the opportunity to enter the contractual relationship at a lower price than in the Windfall treatment. If we regress choices on treatment, we only find a weakly significant effect $(p=$ $.070)$ in the predicted direction. The effect is significant at conventional levels $(p=.002)$ once we control for the choice participants have made in the Baseline. In the Exploitation treatment, risk aversion, loss aversion, regret aversion, and social value orientation do not have explanatory power. ${ }^{5}$ Yet we do find a strong positive correlation (coef $.667, p<.001$ ) with the belief the participant holds about the price the other participant has requested who can take 90 units from this participant in the bad state of Nature. Recall that matching is ex post and random, and that the potential recipient of extra 90 units must not herself have accepted the lottery. Hence the belief only informs participants about the way how others

\footnotetext{
5 The regressions showing this are available from the authors upon request.
} 
react to this situation. Yet the significant result suggests that participants take beliefs as a signal and infer whether it is worth taking the risk.

In $\mathrm{H}_{5}$ we had expected that participants would be even less inclined to to be in the hold-up situation of the Bilateral treatment, compared to two-sided random matching in the Exploitation treatment. This prediction is not supported by the data. We find no significant treatment difference, whether or not we control for choices in the Baseline. We do, however, find a significant difference between the Windfall and the Bilateral treatment (coef $-6.515, p$ $=.027$ ). The critical difference is intentions (to exploit another participant, which play no role in the Windfall treatment, but do in the Exploitation and in the Bilateral treatment).

We finally had predicted in $\mathbf{H}_{6}$ that choices in the Exchange treatment differ from choices in the Bilateral treatment. If we only consider averages, we find no evidence of this effect, nor do we find evidence of an effect if we control for choices in the Baseline. If we add this control variable, we do, however, again find a significant difference between the Windfall and the Exchange treatment (Exchange coef $-5.247 \mathrm{p}=.043$; choice in Baseline coef .746, $p<.001$ ). This suggest that trust is also not critical, but merely the risk of intentional exploitation.

The bottom line is that the fundamental transformation does deter trade. This is due to risk aversion. If someone else can benefit when a trading partner has bad luck, she likes that better than losing money to the experimenter. Yet if the fundamental transformation has occurred, benefit to someone else and exploitation coincide. Being the victim of exploitation is what participants dislike.

Heterogeneity The previous analysis exclusively looks at central tendencies. Yet due to the combination of a within and a between subjects manipulation, we can dig deeper and analyze heterogeneity. Specifically, in the spirit of a difference in difference approach, we compare, separately for each treatment, whether and how participants have changed choices between the Baseline and the respective treatment.

As Figure 2 shows, both the degree and the type of heterogeneity differ markedly across treatments. In the Windfall treatment, $15 \%$ of all participants accept less risk in the treatment than in the Baseline, $40 \%$ accept more risk. By contrast in the Exploitation and in the Bilateral treatments, $26 \%$ and $24 \%$ respectively accept more risk, while $38 \%$ and $37 \%$ accept less risk. Finally in the Exchange treatment 51\% make the same choice as in the Baseline, and only $24 \%$ each shift towards more or less risk. The kernel density plot in the right panel adds cardinal information. If participants move into the direction of less risk, in the Exchange treatment, some of them move very far. In cardinal terms, there is also a descriptive difference between Exploitation and Bilateral. As the large peak in the neighborhood of zero shows, in Exploitation participants either move clearly into the negative direction, or they stick to their previous choice. By contrast, in the Bilateral treatment, there are more small negative shifts, which flattens the density curve. 


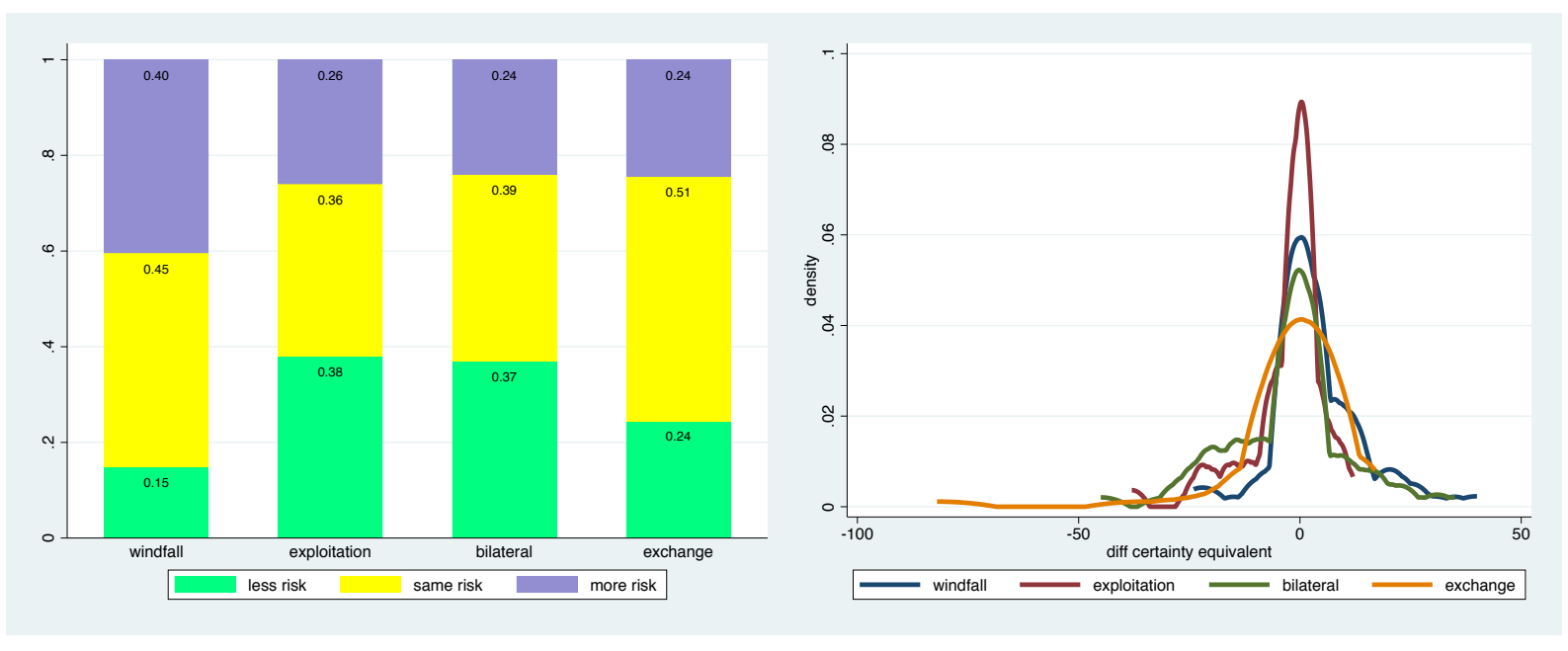

Figure 2

Heterogeneity of Reactions to Treatment

left panel: fraction of participants who choose less, the same or more risk in the treatment, compared with the Baseline right panel: difference in minimum price asked for giving up the opportunity to enter the contractual relationship,

treatment - Baseline, kernel density plots

Table 4 adds statistical tests. The constant in model 1 shows that, in the Windfall treatment (the reference category) participants are $25 \%$ more likely to accept more risk in the treatment than in the Baseline. The significant negative coefficients of the remaining three treatments show that the reactions to treatment are substantially different from the Windfall treatment. ${ }^{6}$ Model 2 conveys the same picture when not analyzing the direction, but the size of the shift between the Baseline and the respective treatment.

\begin{tabular}{|l|l|l|}
\hline & \multicolumn{1}{|c|}{ model 1 } & model 2 \\
\hline & direction of shift & cardinal \\
\hline Exploitation & $-.375^{* *}$ & $-6.770^{* *}$ \\
& $(.152)$ & $(2.517)$ \\
\hline Bilateral & $-.385^{* *}$ & $-6.459^{* *}$ \\
& $(.150)$ & $(2.472)$ \\
\hline Exchange & $-.255^{*}$ & $-5.707^{* *}$ \\
& $(.153)$ & $(2.530)$ \\
\hline cons & $.255^{* * *}$ & $3.830^{* *}$ \\
& $(.109)$ & $(1.807)$ \\
\hline $\mathrm{N}$ & 200 & 200 \\
\hline
\end{tabular}

Table 4

Difference between Baseline and Treatment Across Treatments OLS

dv model 1: dummy that is -1 if participant accepts less risk in the treatment than in the Baseline;

0 if she chooses the same level of risk; 1 if she accepts more risk

$\mathrm{dv}$ model 2: minimum price in treatment - minimum price in Baseline

standard errors in parenthesis

$* * * p<.001, * * p<.05, * p<.1$

6 For the ease of interpretation, we estimate a linear model. Yet multiple effects from an ordered logit specification are comparable. This additional regression is available from the authors upon request. 
In the final step, we use information from post-experimental tests to explain why participants made a different choice in the respective treatment, compared with the Baseline. As we are interested in explaining these shifts, we only use data from participants who have not repeated the choice they had made in the Baseline. In Table 4 we had found pronounced differences between shifts in the Windfall treatment and in the remaining treatments. Once we add any of the control variables, the treatment coefficients are much smaller and treatment effects are almost completely insignificant. This suggests that the controls indeed capture motives behind the decision to make a different choice than in the Baseline.

The significant negative main effect of risk aversion in model 1 of Table 5 shows that for those who accept less risk in the treatment than in the Baseline risk aversion is an important motive. The negative coefficient suggests that these participants are even more concerned about the risk of being exploited, rather than the mere risk of losing money. The significant positive interaction effect shows that this motive is immaterial for participants shifting into the opposite direction. Actually the net effect is insignificant (Wald test, $p=.204$ ), which shows that these participants just don't care about the risk.

In model 2 we find a significant negative main effect of social value orientation. The more participants care about relative income, the more they are inclined to accept less risk in the treatment than in the Baseline. In this specification, the interaction effect is insignificant as is the net effect (Wald test, $p=.928$ ). For participants who accept more risk in the treatment than in the Baseline, social value orientation is not an important motive.

In model 3 we find a significant positive main effect of beliefs. The more risk a participant believes the other participant to accept with whom she is randomly matched, the more risk she accepts herself. Yet as the insignificant interaction and net effect (Wald test, $p=.489$ ) show, these beliefs only matter for participants who accept less risk in the treatment than in the Baseline.

In model 4 we find a weakly significant $(p=.068)$ negative effect of justice sensitivity. The more a participant is concerned about being the victim of an injustice, the more she is inclined to accept less risk in the treatment than in the Baseline. Yet again the interaction effect and the net effect are insignificant (Wald test, $p=290$ ). Again the motive only matters for those who accept less risk than in the Baseline.

In model 5 we jointly control for all explanatory variables. In this specification we only find main effects for beliefs and justice sensitivity. Yet this does not speak against the importance of risk aversion and social value orientation. It just indicates that the explanatory variables are correlated with each other. 


\begin{tabular}{|c|c|c|c|c|c|}
\hline & model 1 & model 2 & model 3 & model 4 & model 5 \\
\hline $\begin{array}{l}\text { positive direction of shift } \\
\text { (indicator }=1 \text { if positive) }\end{array}$ & $\begin{array}{l}17.907^{* * *} \\
(3.010)\end{array}$ & $\begin{array}{l}20.187^{* * *} \\
(3.333)\end{array}$ & $\begin{array}{l}52.280 * * \\
(19.320)\end{array}$ & $\begin{array}{l}21.052^{* *} \\
(6.831)\end{array}$ & $\begin{array}{l}21.422 \\
(23.373)\end{array}$ \\
\hline risk aversion & $\begin{array}{l}-10.965 * * \\
(3.978)\end{array}$ & & & & $\begin{array}{l}-6.768 \\
(4.316) \\
\end{array}$ \\
\hline pos * risk aversion & $\begin{array}{l}16.022^{* *} \\
(5.530) \\
\end{array}$ & & & & $\begin{array}{l}12.080 * \\
(5.798)\end{array}$ \\
\hline social value orientation & & $\begin{array}{l}-.221 * * \\
(.106)\end{array}$ & & & $\begin{array}{l}-.153 \\
(.120)\end{array}$ \\
\hline pos * social value orientation & & $\begin{array}{l}.231 \\
(.152)\end{array}$ & & & $\begin{array}{l}.184 \\
(.162)\end{array}$ \\
\hline $\begin{array}{l}\text { belief about choice of } \\
\text { matched participant }\end{array}$ & & & $\begin{array}{l}.228 * * \\
(.098)\end{array}$ & & $\begin{array}{l}.250 * * \\
(.102)\end{array}$ \\
\hline pos * belief & & & $\begin{array}{l}-.378 \\
(.238)\end{array}$ & & $\begin{array}{l}-.165 \\
(.268)\end{array}$ \\
\hline justice sensitivity victim & & & & $\begin{array}{l}-2.684^{*} \\
(1.457)\end{array}$ & $\begin{array}{l}-3.220 * * \\
(1.574)\end{array}$ \\
\hline pos * justice sensitivity & & & & $\begin{array}{l}1.028 \\
(2.148) \\
\end{array}$ & $\begin{array}{l}1.891 \\
(2.291) \\
\end{array}$ \\
\hline Exploitation & $\begin{array}{l}-3.644 \\
(3.080)\end{array}$ & $\begin{array}{l}-2.621 \\
(3.028)\end{array}$ & $\begin{array}{l}-4.487 \\
(2.897)\end{array}$ & $\begin{array}{l}-3.336 \\
(2.974)\end{array}$ & $\begin{array}{l}-2.721 \\
(3.131)\end{array}$ \\
\hline Bilateral & $\begin{array}{l}-2.783 \\
(3.025)\end{array}$ & $\begin{array}{l}-2.291 \\
(3.003)\end{array}$ & $\begin{array}{l}-.620 \\
(3.107)\end{array}$ & $\begin{array}{l}-2.842 \\
(2.972)\end{array}$ & $\begin{array}{l}-.521 \\
(3.321)\end{array}$ \\
\hline Exchange & $\begin{array}{l}-.5 .363^{+} \\
(3.165)\end{array}$ & $\begin{array}{l}-5.484^{+} \\
(3.193)\end{array}$ & $\begin{array}{l}-5.003 \\
(3.059) \\
\end{array}$ & $\begin{array}{l}-4.267 \\
(3.196) \\
\end{array}$ & $\begin{array}{l}-3.459 \\
(3.298)\end{array}$ \\
\hline cons & $\begin{array}{l}-7.212^{* *} \\
(3.026)\end{array}$ & $\begin{array}{l}-7.372 * * \\
(3.097)\end{array}$ & $\begin{array}{l}-26.740 * * \\
(7.610)\end{array}$ & $\begin{array}{l}-2.944 \\
(4.909) \\
\end{array}$ & $\begin{array}{l}-15.270 * \\
(8.639)\end{array}$ \\
\hline $\mathrm{N}$ & 108 & 115 & 105 & 115 & 98 \\
\hline
\end{tabular}

Table 5

Explaining Difference between Baseline and Treatment Across Treatments OLS

$\mathrm{dv}$ : minimum price in treatment -minimum price in Baseline

choices from participants who have made a different choice in the treatment than in the Baseline

positive direction of shift: dummy that is 1 if participant asks for a higher minimum price in the respective treatment, compared with the Baseline

risk aversion: CRRA score, 0 is risk neutral, 11 participants inconsistent

social value orientation: 0 is selfish belief: from 0 to 100

justice sensitivity: victim scale, mean of 10 items, Likert scale: 0: not concerned, 5: maximally concerned standard errors in parenthesis

$* * * \mathrm{p}<.001, * * \mathrm{p}<.05, * \mathrm{p}<.1$ 


\section{Discussion}

Oliver Williamson has introduced the fundamental transformation as an incentive problem, and as a challenge for the governance of the relationship. In this paper, we use a lab experiment to investigate whether the ensuing challenge for efficient trade is aggravated by behavioral effects. On average, the additional behavioral effects are not strong. The risk of exploitation is a risk with a pecuniary value. Participants mildly (but significantly) dislike this risk. The fact that they sell the opportunity inherent in the fundamental transformation at a price below its expected value indicates that participants are sensitive to this risk. If we only consider averages, the only additional behavioral effect obtains in the Windfall condition. In this condition, participants accept even more risk than in the baseline, where the risk is stochastic. This suggests that the efficiency motive has a behavioral effect in favor, not to the detriment, of the fundamental transformation. Yet this effect disappears as soon as the risk consists of the possibility that the matched participants decide to take money from the participant who has exposed herself to this risk. This suggests that efficiency seeking on the one hand, and aversion to being at the mercy of another person, cancel out.

Yet we see a more pronounced deterrent effect once we allow for reactions to treatment to be heterogeneous. In all treatments, a fraction of participants accept less risk in the treatment than in the Baseline. These participants have been deterred by behavioral effects. Participants shifting into the direction of accepting less risk exist also in the Windfall condition, yet they are much more frequent, and the size of the effect is more pronounced, in the Exploitation and Bilateral conditions. This indicates that a substantial minority of our participants would rather forego the opportunity of a higher profit than exposing themselves to intentional exploitation. In the Exchange condition, the fraction of participants exhibiting behavioral deterrence is again smaller, though. This suggests that trust can at least partly mitigate the additional deterrent effect.

None of the supplementary behavioral measures explains that a participant even more risk when it results from the exposure to a contractual relationship with the risk of exploitation. As the effect is most pronounced in the Windfall condition, the efficiency motive seems to be relevant: if the risk materializes, the money is not destroyed, but benefits another participant. By contrast, participants who accept less risk when a potential loss results from exploitation are motivated by risk aversion, social value orientation, and justice sensitivity. This implies: the story motivating this paper has to be qualified. The prospect of the fundamental transformation does deter trade, largely for the behavioral reasons that we hypothesized. Yet this only holds for a fraction of individuals. In the experiment, this fraction is about a quarter of the participants exposed to a stylized fundamental transformation.

In the interest of isolating behavioral channels, we have simplified the situation. In the field, the fundamental transformation is typically associated with a longer-term relationship. The prospect of being tied to another person for a longer time might have an additional deterrent effect. But it, on the other hand, might also make it easier to accept the transformation, as the risk is not immediate. There might also be illusion of control (Langer 1975, Presson and Benassi 1996), or a better than average effect (Larrick, Burson et al. 2007, Brown 2012). Either 
effect might make the individual believe that she can handle the risk. A further difference is the absence of social context. In the field, contracting partners are likely to collect information about each other before entering the relationship. While the relationship is ongoing, they are likely to monitor each other, and to try to react to warning signals about future exploitation. They might also try to muster threat power to preempt exploitative moves. For all of these reasons, social context might make it easier for individuals to enter a potentially dangerous contractual relationship.

We do therefore not see our results as definitive. But our data shows that the effects of the fundamental transformation transcend incentive effects. Legal and social rules meant to contain the risk of exploitation have the additional benefit of reducing the incidence of behavioral deterrence, resulting from the risk of exploitation. 


\section{REFERENCES}

Adams, William James and Janet L Yellen (1976). "Commodity Bundling and the Burden of Monopoly." Quarterly Journal of Economics 90: 475-498.

Alchian, Armen A and Harold Demsetz (1972). "Production, Information Costs, and Economic Organization." American Economic Review 62(5): 777-795.

Almenberg, Johan, Anna Dreber, Coren L. Apicella and David Rand (2011). Third Party Reward and Punishment. Group Size, Efficiency and Public Goods. Psychology of Punishment. N. Palmetti and J. P. Russo. New York, Nova: 73-92.

Andreoni, James, William T Harbaugh and Lise Vesterlund (2003). "The Carrot or the Stick: Rewards, Punishments and Cooperation." American Economic Review 93: 893-902.

Balliet, Daniel, laetitia B Mulder and Paul AM Van lange (2011). "Reward, Punishment, and Cooperation: A Meta-analysis." Psychological Bulletin 137(4): 594-615.

Becker, Gordon M., Morris H. Degroot and Jacob Marschak (1964). "Measuring Utility by a Single-response Sequential Method." Behavioral Science 9(3): 226-232.

Berg, Joyce, John Dickhaut and Kevin McCabe (1995). "Trust, Reciprocity, and Social History." Games and Economic Behavior 10: 122-142.

Blanco, Mariana, Dirk Engelmann and Hans-Theo Normann (2011). "A Within-Subject Analysis of Other-Regarding Preferences." Games and Economic Behavior 72: 321-338.

Blankenborg, Dieter, Todd Kaplan and Timothy Miller (2012). "A Simple Economic Teaching Experiment on the Hold-Up Problem." Journal of Economic Education 43: 377-385.

Bock, Olaf, Ingmar BAetge ANd ANDREAS NiCKLISCH (2014). "hroot: Hamburg Registration and Organization Online Tool." European Economic Review 71: 117-120.

Bohnet, Iris, Fiona Greig, Benedikt HeRrmann and Richard ZeCkHauser (2008). "Betrayal Aversion. Evidence from Brazil, China, Oman, Switzerland, Turkey, and the United States." American Economic Review: 294-310.

BoHnet, IRIS AND RICHARD ZeCKHAUSER (2004). "Trust, Risk and Betrayal." Journal of Economic Behavior \& Organization 55(4): 467-484.

Brown, JonATHON D (2012). "Understanding the Better than Average Effect. Motives (Still) Matter." Personality and Social Psychology Bulletin 38(2): 209-219.

CARTWRIGHT, DORWIN (1971). "Risk Taking by Individuals and Groups. An Assessment of Research Employing Choice Dilemmas." Journal of Personality and Social Psychology 20: 361-378. 
CASARI, MARCo ANd LUIGI LUINI (2009). "Cooperation under Alternative Punishment Institutions. An Experiment." Journal of Economic Behavior \& Organization 71: 273-282.

Charness, Gary AND URI Gneezy (2012). "Strong Evidence for Gender Differences in Risk Taking." Journal of Economic Behavior \& Organization 83(1): 50-58.

COASE, Ronald H (2000). "The Acquisition of Fisher Body by General Motors." Journal of Law and Economics 43(1): 15-32.

Dohmen, Thomas, Armin Falk, David Huffman, UWe Sunde, Jürgen Schupp and Gert G Wagner (2011). "Individual Risk Attitudes. Measurement, Determinants, and Behavioral Consequences." Journal of the European Economic Association 9(3): 522-550.

DufWenberG, Martin AND URI Gneezy (2000). "Measuring Beliefs in an Experimental Lost Wallet Game." Games and Economic Behavior 30(2): 163-182.

Dufwenberg, Martin, Alec Smith and Matt Van Essen (2013). "Hold - up. With a Vengeance." Economic Inquiry 51(1): 896-908.

ElLINGSEN, TORE AND MAgnus JOHANNESSON (2004). "Is there a Hold - up Problem?" Scandinavian Journal of Economics 106(3): 475-494.

Engelmann, Dirk and Martin Strobel (2004). "Inequality Aversion, Efficiency, and Maximin Preferences in Simple Distribution Experiments." American Economic Review 94: 857869.

Erlei, Mathias and J Philipp Siemer (2014). "Endogenous Property Rights in a Hold - up Experiment." Metroeconomica 65(2): 237-270.

Farrell, Joseph and Paul Klemperer (2007). Coordination and Lock-in. Competition with Switching Costs and Network Effects. Handbook of Industrial Organization. M. Armstrong and R. H. Porter. 3: 1967-2072.

Farrell, Joseph and Carl Shapiro (1989). "Optimal Contracts with Lock-in." American Economic Review 79: 51-68.

Fehr, Ernst, Oliver Hart and Christian Zehnder (2011). "Contracts as Reference Points. Experimental Evidence." American Economic Review 101(2): 493-525.

Fehr, ERnst, Oliver Hart And Christian Zehnder (2015). "How Do Informal Agreements and Revision Shape Contractual Reference Points?" Journal of the European Economic Association 13(1): 1-28.

Fehr, ERnSt And Klaus M. SChMidt (1999). "A Theory of Fairness, Competition, and Cooperation." Quarterly Journal of Economics 114: 817-868. 
Fehr, ERnst, Christian Zehnder and Oliver Hart (2009). "Contracts, Reference Points, and Competition. Behavioral Effects of the Fundamental tTansformation." Journal of the European Economic Association 7(2-3): 561-572.

FISCHBACHER, URS (2007). "z-Tree. Zurich Toolbox for Ready-made Economic Experiments." Experimental Economics 10: 171-178.

Fullenkamp, Connel, Rafael Tenorio and Robert Battalio (2003). "Assessing Individual Risk Attitudes Using Field Data From Lottery Games." Review of Economics and Statistics 85: 218-226.

GÄCHTER, SIMON, ERIC J. JohnSON AND ANDREAS HERRMANn (2007). Individual-Level Loss Aversion in Riskless and Risky Choices. http://www.nottingham.ac.uk/economics/cedex/papers/2007-02.pdf.

Güth, Werner, Rolf Schmittberger and Bernd Schwarze (1982). "An Experimental Analysis of Ultimatum Bargaining." Journal of Economic Behavior and Organization 3: 367-388.

HART, Oliver ANd JOHn MoORe (2008). "Contracts as Reference Points." Quarterly Journal of Economics 123: 1-48.

Holt, Charles A. AND Susan K. Laury (2002). "Risk Aversion and Incentive Effects." American Economic Review 92: 1644-1655.

Hoppe, Eva I ANd Patrick W Schmitz (2011). "Can Contracts Solve the Hold-up Problem? Experimental Evidence." Games and Economic Behavior 73(1): 186-199.

Johnson, Noel D. And AleXandra A. Mislin (2011). "Trust Games. A Meta-analysis." Journal of Economic Psychology 32(5): 865-889.

Kahneman, Daniel (1992). "Reference Points, Anchors, Norms, and Mixed Feelings." Organizational Behavior and Human Decision Processes 51: 296-312.

Kahneman, Daniel, Jack L. Knetsch and Richard H. Thaler (1991). "Anomalies. The Endowment Effect, Loss Aversion, and Status Quo Bias." Journal of Economic Perspectives 5: 193206.

KLEIN, BeNJAMIN (1988). "Vertical Integration as Organizational Ownership. The Fisher BodyGeneral Motors Relationship Revisited." Journal of Law, Economics, \& Organization 4(1): 199-213.

KLeIN, Benjamin (2000). "Fisher-General Motors and the Nature of the Firm." Journal of Law and Economics 43(1): 105-142.

Klein, Benjamin, Robert G Crawford and Armen A Alchian (1978). "Vertical Integration, Appropriable Rents, and the Competitive Contracting Process." Journal of Law and Economics 21(2): 297-326. 
KöszegI, Botond and Matthew Rabin (2006). "A Model of Reference-Dependent Preferences." Quarterly Journal of Economics 121: 1133-1165.

LANGer, ElLen J. (1975). "The Illusion of Control." Journal of Personality and Social Psychology 32: 311-328.

Larrick, Richard P, Katherine A Burson and Jack B Soll (2007). "Social Comparison and Confidence. When Thinking you're Better than Average Predicts Overconfidence (and When it Does not)." Organizational Behavior and Human Decision Processes 102(1): 76-94.

Liebowitz, Stan J and Stephen E Margolis (1995). "Path Dependence, Lock-in, and History." Journal of Law, Economics, \& Organization 11: 205-226.

McAfee, R Preston, John McMillan and Michael D Whinston (1989). "Multiproduct Monopoly, Commodity Bundling, and Correlation of Values." Quarterly Journal of Economics 104(2): 371-383.

Murphy, Ryan O. And Kurt A. ACKermann (2014). "Social Value Orientation: Theoretical and Measurement Issues in the Study of Social Preferences." Personality and Social Psychology Review 18: 13-41.

NALEBUfF, BARRY (2004). "Bundling as an Entry Barrier." Quarterly Journal of Economics 119(1): 159-187.

Presson, Paul K. And Victor A. Benassi (1996). "Illusion of Control. A Meta-Analytic Review." Journal of Social Behavior and Personality 11: 493-510.

SAVAGE, LeONARD J. (1954). The Foundations of Statistics. New York,, Wiley.

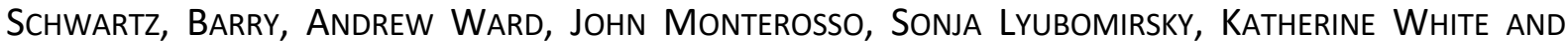
DARRIN R LEHMAN (2002). "Maximizing versus Satisficing. Happiness is a Matter of Choice." Journal of Personality and Social Psychology 83(5): 1178-1197.

SELTEN, REINHARD (1967). Die Strategiemethode zur Erforschung des eingeschränkt rationalen Verhaltens im Rahmen eines Oligopolexperiments. Beiträge zur experimentellen Wirtschaftsforschung. E. Sauermann. Tübingen, Mohr: 136-168.

Sloof, Randolph, Joep Sonnemans and Hessel Oosterbeek (2004). "Specific Investments, Holdup, and the Outside Option Principle." European Economic Review 48(6): 1399-1410.

TVersky, Amos and Daniel Kahneman (1991). "Loss Aversion in Riskless Choice. A ReferenceDependent Model." Quarterly Journal of Economics 106: 1039-1061.

Van de Ven, Niels and Marcel Zeelenberg (2011). "Regret Aversion and the Reluctance to Exchange Lottery Tickets." Journal of Economic Psychology 32(1): 194-200. 
Williamson, Oliver E. (1985). The Economic Institutions of Capitalism. Firms, Markets, Relational Contracting. New York London, Free Press ; Collier Macmillan.

Zeelenberg, Marcel and Jane Beattie (1997). "Consequences of Regret Aversion 2. Additional Evidence for Effects of Feedback on Decision Making." Organizational Behavior and Human Decision Processes 72(1): 63-78.

Zeelenberg, Marcel, Jane Beattie, Joop Van der Pligt and Nanne K De Vries (1996). "Consequences of Regret Aversion. Effects of Expected Feedback on Risky Decision Making." Organizational Behavior and Human Decision Processes 65(2): 148-158. 


\section{Appendix \\ Instructions}

\section{General Instructions}

You are now participating in an experiment. If you read the following instructions carefully, you can - depending on the decision you make - earn a substantial amount of money. It is therefore important that you take your time for understanding the instructions.

Please do not communicate with other participants during the experiment. If you have questions, please approach us.

All your decisions will remain absolutely anonymous.

The experiment consists of eight independent parts and a survey. Your decisions in one part of the experiment will not influence your earnings and choices in other parts of the experiment. Before the beginning of further parts of the experiment, you will receive instructions for the respective part.

Feedback about all parts of the experiment is withheld until the very end of the entire experiment. At this point we will also inform you about your earnings from the individual parts of the experiment.

For participating in the experiment you earn upfront

$5 €$.

In all parts of the experiment we calculate your earnings in our experimental currency ECU. In the end of the experiment, we exchange ECU into Euro. We will explain the exchange rate separately for each part.

In the end of the experiment, the computer will decide whether the first or the second part of the experiment is paid out. Both is equally likely. All other parts of the experiment are paid out with certainty.

\section{First Part}

The first part of the experiment has two stages. In the first stage you decide whether you want to enter the second stage. If you enter the second stage of this part of the experiment, you obtain 100 ECU with probability $80 \%$, and 10 ECU with probability $20 \%$.

We want to learn how highly you value the opportunity to participate in the second stage. To make sure that your response is truly reliable, we do not simply ask. We use a somewhat more 
complicated procedure. With this procedure, nobody can benefit from making a false statement.

The procedure works as follows: We ask you to tell us a number between 0 and 100 . At the end of the experiment, the computer will randomly draw a number from the same interval, i.e. between 0 and 100. All numbers in this interval are equally likely to be drawn. If the number that you have indicated is smaller than the number drawn by the computer, you receive the number drawn by the computer in ECU and do not enter the second stage of this part of the experiment. If the number drawn by the computer is the same as the number you have indicated or larger, you enter the second stage of this part of the experiment.

Why is it your best response to tell the number that corresponds to your true valuation for refraining from participating in the second stage of the experiment? Let us assume you value the possibility to participate in the second stage of the experiment at $90 \mathrm{ECU}$. Yet you indicate the number 40 . The computer picks 60 . Then you receive 60 . You thus give away the opportunity to participate in the second stage too cheaply. Let us, by contrast, assume that you value participating in the second stage of the experiment at $50 \mathrm{ECU}$. Yet you indicate the number 70. The computer again picks 60 . You then participate in the second stage of the experiment, although you could have received 60 , i.e. an amount higher than your valuation.

When is is worth participating in the second stage of the experiment? There is no general answer. To find this out, we run this experiment. But we can tell you which choice maximizes your expected profit. Recall: if you participate in the second stage of the experiment, with probability $80 \%$ you receive $100 \mathrm{ECU}$. In expectation this is $0.8 * 100=80 \mathrm{ECU}$. With probability $20 \%$ you receive $10 \mathrm{ECU}$. In expectation this is $0.2 * 10=2 \mathrm{ECU}$. If you are not bothered by uncertainty about your earnings, you maximize your earnings by indicating the number $80+$ $2=82 \mathrm{ECU}$. If you prefer as somewhat smaller, but certain payment over participating in the second stage of the experiment, indicate a number lower than $82 \mathrm{ECU}$. If you do not want to be deprived of the opportunity to earn $100 \mathrm{ECU}$, indicate a higher than $82 \mathrm{ECU}$.

About all random draws and about your earnings from this part of the experiment we will only inform you at the very end of the entire experiment.

In this part of the experiment, the following exchange rate applies

$$
10 \mathrm{ECU}=1 €
$$

\section{control questions}

1. You have indicated that you do not want to enter the second stage of this part of the experiment if you receive $66 \mathrm{ECU}$. The computer draws the number 52 . What is the effect?
a) you receive 66
b) you receive 52
c) you proceed to stage 2 of the experiment 
2. You have indicated that you do not want to enter the second stage of this part of the experiment if you receive $48 \mathrm{ECU}$. The computer draws the number 62 . What is the effect?
a) you receive 62
b) you receive 48
c) you proceed to stage 2 of the experiment

\section{Second Part}

The second part of the experiment does also have two stages. The first stage is exactly as the first stage in the first part of the experiment. We again want to know how highly you value participating in the second stage of the experiment. What differs is the second stage. If you participate in the second stage of the experiment,

\section{$<$ Windfall $>$}

you obtain 100 ECU with probability $80 \%$. With probability $20 \%$ you obtain 10 ECU, and another randomly selected participant obtains the additional amount of 90 ECU. This additional payment is irrespective of the choice this participant has made in the first stage of this part of the experiment and, if she has decided to enter the second stage, of her own payoff from the second stage of this part of the experiment.

You will yourself also be randomly matched with a third participant. In case this participant has entered the second stage of this part of the experiment, with $20 \%$ probability she only obtains $10 \mathrm{ECU}$, and you additionally obtain $90 \mathrm{ECU}$.

Hence at the second stage of this part of the experiment you are paired with two other participants. One participant potentially receives more money and your payment from the experiment is reduced. Another participant potentially receives less money and your payment from the experiment is increased.

\section{$<$ Exploitation $>$}

you obtain 100 ECU with probability $80 \%$. With probability $20 \%$ you obtain $10 \mathrm{ECU}$, if another randomly selected participant decides to keep the additional amount of 90 ECU for herself. This additional payment is irrespective of the choice this participant has made at the first stage of this part of the experiment and, if she has decided to enter the second stage, of her own payoff from the second stage.

You will yourself also be randomly matched with a third participant. In case this participant has entered the second stage of this part of the experiment, with $20 \%$ probability it will be for you to decide whether this third participant only obtains $10 \mathrm{ECU}$, and you additionally obtain 90 ECU. 
Hence at the second stage of the experiment you are paired with two other participants. One participant potentially receives more money and your payment from the experiment is reduced. Another participant potentially receives less money and your payment from the experiment is increased.

Before the computer has implemented all random choices, we ask all participants whether they want to keep 90 ECU for themselves in case this becomes possible. The decision to keep $90 \mathrm{ECU}$ is executed in case this becomes possible.

\section{$<$ Bilateral>}

you are randomly matched with another participant. This participant is randomly selected from those participants who enter the second stage of this part the experiment. In case the number of participants who enter the second stage of the experiment is odd, one of them is randomly selected and receives the amount the computer has drawn for her in the first stage. Each participant who has decided to enter the second stage is singled out with the same probability for receiving the payoff from the first stage of the experiment in case the number of participants who have entered the second stage is odd.

In the second stage of the experiment, you obtain 100 ECU with probability $80 \%$. With probability $20 \%$ you obtain $10 \mathrm{ECU}$, if the other participant keeps the additional amount of 90 ECU for herself. This additional payment is independent of the question whether you have the possibility to obtain the additional amount of $90 \mathrm{ECU}$ from the other participant with whom you have been matched, and whether you choose to do so.

The participant with whom you have been matched obtains 100 ECU with probability $80 \%$. With probability $20 \%$ she obtains 10 ECU if you decide to keep the additional amount of 90 ECU for yourself. This additional payment is independent of the question whether the other participant has the possibility to obtain the additional amount of $90 \mathrm{ECU}$ from you, and whether she chooses to do so.

Hence in this part of the experiment you are paired with one other participant. The other participant potentially receives more money and your payment from the experiment is reduced. The other participant potentially receives less money and your payment from the experiment is increased.

Before the computer has implemented all random choices, we ask all participants whether they want to keep 90 ECU for themselves in case this becomes possible. The decision to keep $90 \mathrm{ECU}$ is executed in case this becomes possible.

\section{$<$ Exchange>}

In the first part of the experiment you are randomly matched with one other participant. This part of the experiment has two stages. In the first stage you and the participant with whom you have been matched decide whether you want to enter the second stage. To that end we will ask both of you to tell us a number between 0 and 100. At the end of the experiment, separately for each of you the computer will randomly draw a number from the same interval, 
i.e. between 0 and 100. All numbers in this interval are equally likely to be drawn. If the number that you have indicated is smaller than the number drawn by the computer, you receive the number drawn by the computer and do not enter the second stage of the experiment. If the number drawn by the computer is the same as the number you have indicated or larger, you enter the second stage of the experiment. We apply the same procedure to the participant with whom you have been matched.

The second stage of the experiment is only played out if both of you have decided to enter the second stage. If you enter at the second stage, you obtain $100 \mathrm{ECU}$ with probability $80 \%$. With probability $20 \%$ you obtain $10 \mathrm{ECU}$, if the other participant decides to keep the additional amount of $90 \mathrm{ECU}$ for herself. This additional payment is independent of the question whether you have the possibility to obtain the additional amount of $90 \mathrm{ECU}$ from the other participants, and whether you choose to do so.

The participant with whom you have been matched obtains 100 ECU with probability $80 \%$. With probability $20 \%$ she obtains 10 ECU if you decide to keep the additional amount of 90 ECU for yourself. This additional payment is independent of the question whether the other participant has the possibility to obtain the additional amount of 90 ECU from you, and whether she chooses to do so.

Hence at the second stage of the experiment you are paired with one other participant. The other participant potentially receives more money and your payment from the experiment is reduced. The other participant potentially receives less money and your payment from the experiment is increased.

Before the computer has implemented all random choices, we ask all participants whether they want to keep 90 ECU for themselves in case this becomes possible. The decision to keep $90 \mathrm{ECU}$ is executed in case this becomes possible.

$<$ all treatments>

You will be informed about all random draws, and about your payoff from this part of the experiment, only at the very end of the entire experiment.

In this part of the experiment, the following exchange rate applies

$10 \mathrm{ECU}=1 €$.

\section{Third Part}

$<$ Windfall $>$

In the second part of the experiment, you have been randomly matched with two other participants. All participants have made the same decision in the first part of the experiment. 
Recall that each participant has received the number drawn by the computer in ECU, and did not enter the second stage of the first part, if the number she has indicated was below the number drawn by the computer. What do you believe has been the number indicated by the participant with whom you have been matched and who could receive an additional payoff from you? If you get this number exactly right, you additionally receive $10 \mathrm{ECU}$. If your estimate is no more than +/- 5 away from the actual number, you additionally receive $5 \mathrm{ECU}$.

\section{$<$ Exploitation $>$}

In the second part of the experiment, you have been randomly matched with two other participants. All participants have made the same decision in the first part of the experiment. Recall that each participant has received the number drawn by the computer in ECU, and did not enter the second stage of the first part, if the number she has indicated was below the number drawn by the computer. What do you believe has been the number indicated by the participant with whom you have been matched and who could receive an additional payoff from you? If you get this number exactly right, you additionally receive $10 \mathrm{ECU}$. If your estimate is no more than +/- 5 away from the actual number, you additionally receive $5 \mathrm{ECU}$.

Do you think that this participant has decided to take 90 ECU from you, should this become possible? If your estimate is correct, you additionally receive 5 ECU.

\section{$<$ Bilateral, Exchange>}

In the second part of the experiment, you have been matched with another participant. All participants have made the same decision in the first part of the experiment. Recall that each participant has received the number drawn by the computer in ECU, and did not enter the second stage of the first part, if the number she has indicated was below the number drawn by the computer. What do you believe has been the number indicated by the participant with whom you have been matched? If you get this number exactly right, you additionally receive 10 ECU. If your estimate is no more than +/- 5 away from the actual number, you additionally receive 5 ECU.

Do you think that this participant has decided to take 90 ECU from you, should this become possible? If your estimate is correct, you additionally receive $5 \mathrm{ECU}$.

\section{Fourth Part}

In this part of the experiment, you decide on your own. We show you 10 pairs of lotteries. Please decide for each pair, which of the two lotteries you prefer. The computer will decide ex post which of the 10 pairs of lotteries is payoff relevant. Each pair is chosen with the same probability. Lottery pairs differ in terms of the probability that the higher or the lower payoff obtains. The computer will decide for the chosen pair of lotteries, which of the two payoffs obtains. You will receive the payoff for the lottery that you have chosen for the pair in question. 
The amounts shown on the screen will be paid out in $€$.

\section{Fifth Part}

In this part of the experiment you decide on your own as well. Please decide for each of the six lotteries whether you want to accept or reject the lottery. If you reject the lottery, you obtain $0 \mathrm{ECU}$. At the end of the entire experiment, the computer will decide which lottery is payoff relevant. If you have accepted this lottery, the computer will play out the lottery. Each of both payoffs is equally probable.

\begin{tabular}{|l|l|l|l|l|}
\hline Lotterie & $\begin{array}{l}\text { (50\% probability of }) \\
\text { gain }\end{array}$ & $\begin{array}{l}(50 \% \text { probability of }) \\
\text { loss }\end{array}$ & accept & reject \\
\hline 1 & 60 & 20 & & \\
\hline 2 & 60 & 30 & & \\
\hline 3 & 60 & 40 & & \\
\hline 4 & 60 & 50 & & \\
\hline 5 & 60 & 60 & & \\
\hline 6 & 60 & 70 & & \\
\hline
\end{tabular}

In this part of the experiment, the exchange rate is

$100 \mathrm{ECU}=1 €$

\section{Sixth Part}

In this part of the experiment, we ask you to answer the following five questions. There is no right or wrong answer. We are interested in your assessment. Please formulate this assessment on a scale from 1 to 7 .

1. Whenever I make a choice, I'm curious about what would have happened if I had chosen differently.

2. Whenever I make a choice, I try to get information about how the other alternatives turned out.

3. If I make a choice and it turns out well, I still feel like something of a failure if I find out that another choice would have turned out better.

4. When I think about how I'm doing in life, I often assess opportunities I have passed up.

5. Once I make a decision, I don't look back.*

Scale:1 = completely disagree, $2=$ disagree, 3 = slightly disagree, $4=$ neither agree nor disagree, 5 = slightly agree, 6 = agree, and 7 = completely agree. ${ }^{*}$ Reversed Items 


\section{Seventh Part}

In this part of the experiment, we ask each participant to decide about 6 allocations. In the end of the experiment, one of these decisions will randomly be chosen to be payoff relevant.

In this part of the experiment, the exchange rate is

$$
100 \mathrm{ECU}=1 €
$$

\section{Eighth Part}

In this part of the experiment, you are also randomly matched with another participant. This matching is independent from matchings in earlier parts of the experiment. In this part of the experiment, there are two roles, $A$ and $B$. Which role you have will only be determined by the computer at the end of the entire experiment. We therefore ask you to make a decision in each of both roles.

A receives an endowment of $10 \mathrm{ECU}$. She may keep this endowment, or send 5 or $10 \mathrm{ECU}$ to $B$. Any amount sent to $B$ is tripled. Hence if $A$ has sent $5 E C U, B$ receives $15 E C U$; and if $A$ has sent $10 \mathrm{ECU}, \mathrm{B}$ receives $30 \mathrm{ECU}$. $B$ may send back to $A$ one of the amounts listed on the following screen.

In this part of the experiment, the exchange rate is

$$
10 \mathrm{ECU}=1 €
$$

\begin{tabular}{|c|c|c|c|c|c|c|}
\hline A sends & B receives & \multicolumn{5}{|c|}{ B sends } \\
\hline 0 & 0 & 0 & 0 & 0 & 0 & 0 \\
\hline 5 & 15 & 10 & 7.5 & 5 & 2.5 & 0 \\
\hline 10 & 30 & 20 & 15 & 10 & 5 & 0 \\
\hline
\end{tabular}

